\title{
No increase in headache after previous intracranial infections: a historical cohort study (The Nord-Trøndelag Health Survey)
}

\author{
M Linde ${ }^{1 *}$, HA Langnes ${ }^{1}$, K Hagen $^{1}$, K Bergh $^{2}$, LJ Stovner $^{1}$ \\ From The European Headache and Migraine Trust International Congress \\ London, UK. 20-23 September 2012
}

\section{Introduction}

Despite the absence of robust scientific evidence, it is today generally accepted that the acute headache typical for intracranial infections can develop into permanent headache complaints.

\section{Objective}

The widespread concept of chronic post-infection headache was explored in the first, large, longitudinal, population-based study.

\section{Methods}

Data on confirmed exposure to intracranial infections amongst all adult inhabitants in a geographical area during a 20-year period were assembled from hospital records. Surviving individuals were later invited to the third Nord-Trøndelag Health Survey (HUNT 3), where $39,690(42 \%)$ of 94,194 invited inhabitants aged $\geq 20$ years responded to a validated headache questionnaire. Using logistic regression, the 1-year prevalence of headache and its subtypes according to the diagnostic criteria of the International Headache Society was assessed and compared between those with and without previous confirmed intracranial infection. Age and sex were used as covariates.

\section{Results}

Overall, 43 participants were identified with earlier intracranial infection, whereof three had more than one infection: bacterial meningitis $(n=19)$, lymphocytic meningitis $(n=18)$, encephalitis $(n=9)$, and brain abscess $(n=1)$. The mean interval from infection to participation in HUNT 3 was 11.2 (range 1.5-19.7) years. There was no significant increase in the prevalence of headache (OR 1.10, 95\% CI 0.58-2.07), its subtypes (migraine, or tension-type headache), or chronic daily headache (OR 1.85, 95\% CI 0.45-7.68) amongst participants with previous intracranial infection compared with the surrounding population.

\section{Conclusion}

This study challenges the existence of chronic post-bacterial meningitis headache and does not indicate the presence of other long-term headaches induced by intracranial infection.

\section{Conflict of interest}

None.

\section{Author details}

'Department of Neuroscience, Norwegian University of Science and Technology, Norway. ${ }^{2}$ Department of Microbiology, St. Olavs University

Hospital, Trondheim, Norway.

Published: 21 February 2013

\section{References}

1. Bohr V, Hansen B, Kjersem H, Rasmussen N, Johnsen N, Kristensen HS, et al: Sequelae from bacterial meningitis and their relation to the clinical condition during acute illness, based on 667 questionnaire returns. Part II of a three part series. J Infect 1983, 7(2):102-110.

2. Headache Classification Subcommittee of the International Headache Society: The International Classification of headache disorders. Cephalalgia 2004, 24(Suppl 1):1-160.

doi:10.1186/1129-2377-14-S1-P148

Cite this article as: Linde et al:: No increase in headache after previous intracranial infections: a historical cohort study (The Nord-Trøndelag Health Survey). The Journal of Headache and Pain 2013 14(Suppl 1):P148. 